\title{
Digital Health in Canadian Schools of Nursing-Part B: Academic Nurse Administrators' Perspectives
}

Lynn M. Nagle

University of New Brunswick, lynn.nagle@unb.ca

Manal Kleib

University of Alberta, kleib@ualberta.ca

Karen Furlong

University of New Brunswick, kfurlong@unb.ca

Follow this and additional works at: https://qane-afi.casn.ca/journal

Part of the Nursing Administration Commons, and the Other Nursing Commons

\section{Recommended Citation}

Nagle, Lynn M.; Kleib, Manal; and Furlong, Karen (2020) "Digital Health in Canadian Schools of Nursing-Part B: Academic Nurse Administrators' Perspectives," Quality Advancement in Nursing Education - Avancées en formation infirmière: Vol. 6: Iss. 3, Article 8.

DOI: https://doi.org/10.17483/2368-6669.1256

This Article is brought to you for free and open access by Quality Advancement in Nursing Education - Avancées en formation infirmière. It has been accepted for inclusion in Quality Advancement in Nursing Education - Avancées en formation infirmière by an authorized editor of Quality Advancement in Nursing Education - Avancées en formation infirmière. 


\section{Digital Health in Canadian Schools of Nursing-Part B: Academic Nurse Administrators' Perspectives}

\section{Cover Page Footnote}

On behalf of the Canadian nursing community, we would like to express our thanks and appreciation for the funding and support provided by Canada Health Infoway in completing this study. In addition, the support received from the Canadian Association of Schools of Nursing (CASN) was invaluable in the dissemination of surveys, qualitative data collection and translation of both surveys and this final report. We would also like to thank all the nursing informatics experts, educators and researchers who provided input and review of the study proposal and survey designs. Finally, a special note of appreciation to participants, your obvious commitment to preparing future nurses for practice is truly inspirational. Au nom de la communauté des infirmières canadiennes, nous souhaitons exprimer nos sincères remerciements pour le soutien financier obtenu par Santé Canada Infoway qui a rendu cette recherche possible. De plus, nous souhaitons souligner le soutien inestimable reçu de l'Association canadienne des écoles de sciences infirmières (ACÉSI) pour la diffusion des sondages, la collecte des données qualitatives et la traduction des sondages et du rapport final. Nous souhaitons également remercier toutes les expertes infirmières en informatique, les formatrices et chercheuses qui ont fourni des commentaires sur la demande de subvention et sur l'élaboration du sondage. Enfin, nous formulons une appréciation toute particulière aux participantes; votre engagement à préparer les futures infirmières à la pratique est une source de grande inspiration. 


\section{Digital Health in Canadian Schools of Nursing - Part B: Academic Nurse Administrators' Perspectives}

In recent years, technological innovations and events such as the COVID-19 pandemic have contributed to a significant shift in approaches to healthcare delivery worldwide (Canadian Nurses Association [CNA] \& Canadian Nursing Informatics Association [CNIA], 2017; Denadai, 2020; Peek, Sajan \& Scott, 2020; Pepito \& Locsin, 2018). This pandemic has particularly illuminated the importance of technology in containing the spread of disease, providing support for surveillance, testing, contact tracing, quarantine monitoring, and clinical management (Whitelaw, Mamas, Topol, Van Spall, 2020). Further, because of imposed physical distancing constraints, many countries have seen an unprecedented use of "virtual" care which may become the norm for the future (Denadai, 2020; Peek, Sajan \& Scott, 2020). According to Denadai: In a post-COVID-19 era, a possible change in healthcare could see "in-person" health care as option B. The future starts now, and clinicians should act accordingly (p. e1967). To this end, more than ever before it is imperative that digital health become a core thread embedded within every undergraduate nursing curriculum to ensure the adequate preparation of nurses for practice now and into the future.

\section{Digital Health and Informatics}

The World Health Organization (WHO) defines digital health as: "the field of knowledge and practice associated with any aspect of adopting digital technologies to improve health, from inception to operation" (WHO, 2019, p. 2). Canada Health Infoway (n.d.) defines digital health as: "the use of information technology/electronic communication tools, services and processes to deliver health care services or to facilitate better health" (para. 1). The widespread adoption and use of information and communication technologies (ICTs) includes new clinical tools (e.g., 
electronic health records [EHR], self-management applications for smartphones) and new service delivery processes (e.g., mobile and virtual care). While these tools and approaches provide opportunities to improve the health of citizens and communities, they also challenge health professionals to understand and know how to use ICTs in the context of care (Canada Health Infoway, 2017; Nelson \& Staggers, 2018).

The term informatics refers to the "science of how to use data, information, and knowledge to improve human health and the delivery of healthcare services (AMIA, n.d. a). Clinical informatics refers to the "application of informatics and information technology to deliver healthcare services" (AMIA, n.d b, para.1). This definition describes how clinicians (regardless of discipline) use information in the context of care and includes topics ranging from system design, implementation, adoption to various technology applications such as decision support tools, order entry technologies, and clinical documentation (AMIA, n.d b). The term health informatics is often viewed as an umbrella term encompassing the different subspecialties in the field, such as medical informatics, pharmacy informatics, nursing informatics, public health informatics, as each discipline has unique information needs and disciplinary knowledge (Nelson \& Staggers, 2018). Health informatics has also been described by the United States National Library of Medicine as the "interdisciplinary study of the design, development, adoption and application of IT-based innovations in healthcare services delivery, management and planning (para 1).” In Canada, we refer to health informatics as digital health (Canada Health Infoway, n.d).

While definitions of Nursing Informatics (NI) have evolved over the years, the most widely accepted definition in Canada and globally is the one proposed by the International Medical Informatics Association [IMIA] Nursing Informatics Special Interest Group, which 
defined NI as: "science and practice [that] integrates nursing, its information and knowledge, with the management of information and communication technologies to promote the health of the people, families, and communities worldwide (IMIA, 2009, para 2). As innovation and technology continue to evolve, these various lenses on informatics will help each and every discipline, including nursing, to keep pace and advance disciplinary knowledge in informatics as it applies to each (Staggers \& Nelson, 2018). Preparing nurses to think about the expansive field of informatics as a science and practice, as opposed to technical aspects associated with computer proficiency and training, is extremely important to advance core nursing competence. Digital health tools are intended to complement nurses' work rather than replace it (Huston, 2013; Skiba, 2017).

\section{Canadian Association Schools of Nursing (CASN) and Digital Health/Informatics}

Almost two decades ago, results of a national Canadian study indicated less than $30 \%$ of Schools of Nursing reported having digital health/informatics content integrated into their basic entry to practice programs, either theoretical or applied (AUTHOR, 2004). This finding was not surprising as the adoption of ICTs in healthcare, and particularly their use by nurses, was limited at that time. In addition, informatics competency expectations for registered nurses had yet to be defined. Since that time, core curricula have been gradually changing and digital health/informatics competencies are being recognized as essential for nurses to practice safely in digitally enabled workplaces (Skiba, Connors, \& Jeffries, 2008; Skiba, 2017; Canadian Association of Schools of Nursing, 2015; Darvish, Bahramnezhad, Keyhanian, \& Navidhamidi, 2014; Greiner \& Knebel, 2003). To that end and as the national voice for nursing education, the Canadian Association of Schools of Nursing (CASN) took on a leading role in addressing informatics within Canadian nursing education. 
CASN is a voluntary, bilingual association representing all universities and colleges offering undergraduate or graduate degrees in nursing in Canada. It serves a number of functions including: accrediting nursing programs; ensuring quality of nursing education in Canada through standards, education and scholarship; promoting advancement of nursing knowledge; integrating theory, research and practice; influencing public policy; and providing a forum for issues in nursing education and research in Canada.

CASN led a number of strategic initiatives to increase nursing capacity in relation to the emerging ubiquity of digital health solutions and approaches (CASN, n.d). These initiatives include: (1) the delineation of core entry-to-practice nursing informatics (NI) competencies for registered nurses (CASN, 2012); (2) the development of teaching tools and other resources to facilitate educators' integration of these competencies within undergraduate nursing education (CASN, 2013; 2016; 2019); and (3) the provision of faculty professional development and mentorship programs in informatics (AUTHOR, 2016). Most recently, in 2019 CASN led the development of an interactive, self-directed program to support the development of nurse educators' knowledge of digital health (see: https://digitalhealth.casn.ca/).

Anecdotal evidence emerging from CASN's digital health initiatives suggested a number of Schools of Nursing use a variety of approaches (e.g., undergraduate and graduate guest lectures and elective courses, EHR training) to integrate digital health into nursing curricula. However, despite extensive work completed to date, these CASN initiatives have been largely silent on the role of academic nursing administrators in advancing digital health capacity and curricular integration of the same. Moreover, the status of actual curricula content integration and educator capacity in digital health were underreported or essentially unknown since the national study conducted more than 15 years ago (AUTHOR, 2004). 


\section{The Role of Academic Nurse Administrators in Advancing Digital Health}

In clinical practice settings, the role of the nurse administrator has largely focused on “supporting system goals through improving clinical performance...[being a] champion for patient safety, quality care, and evidence-based practice" (Engelbright \& Perlin, 2008, p. 189). Traditionally, nurse administrators lead and direct strategies to improve patient and organizational outcomes across disciplines, contending with a myriad of patient, professional, and health system issues. In comparison, academic nurse administrators have equally complex roles and challenges but have been described as the leaders "who will shape the future of our profession" (Bouws, 2018, p. 80). Whether designated as Dean, Director or Chair, the chief nurse administrator role in nursing education is deemed "one of the most critical leadership positions within the profession" (Morton, 2014, 279). Effective academic administrators are key to the preparation of nurses equipped to deal with the current and emerging complexities of healthcare. Ideally, they are strategic thinkers, "visioning for the preferred future, challenging the status quo, and embracing change and chaos as unique opportunities" (Morton, 2014, p. 279). They also provide the direct interface between educators, clinical practice environments, regulators and accrediting bodies. It is therefore incumbent on academic nurse administrators to ensure that nursing curricula are relevant and appropriate to the preparation of nurses for contemporary clinical practice. Furthermore, it is equally important to provide their educators with support and resources needed for effective curricular integration, combined with opportunities for the development of digital health/informatics competency among nurse educators themselves (AUTHOR, 2020). The development of digital health knowledge and informatics competency among graduate nurses is no longer optional but essential to ensuring curricular relevance. Academic leaders and educators are jointly accountable for the adoption of curricula that include 
learning outcomes designed to prepare nurses for practice in digitally-enabled healthcare systems.

\section{Purpose \& Objectives}

In 2018, we conducted a mixed method (Driessnack, Sousa, \& Mendes, 2007) study to understand the current state of digital health and informatics content integration in nursing curricula from the perspectives of academic nurse administrators and nurse educators within Canadian Schools of Nursing. Nurse educator findings (Part A) have been detailed in a previous publication (AUTHOR, 2020). Overall, these findings (Part A) demonstrated a general lack of awareness of the CASN resources and also reflected inconsistent digital health integration in undergraduate nursing curricula. Educators also reported varying levels of intentional planning and administrative support to realize comprehensive curricular integration of digital health theory and application (AUTHOR, 2020).

The purpose of this paper (Part B) is to identify the current capacity and delivery of digital health theory and application in Canadian undergraduate nursing programs from the perspective of academic nurse administrators. Specifically, we provide: 1) a brief description of administrator pertinent aspects of the study methodology, 2) an overview of the results specific to nurse administrators, 3) a discussion of comparative results of administrator versus educator perspectives, and 4) recommended strategies for nurse administrators to foster the integration of digital health content and skills into undergraduate curricula in Canadian Schools of Nursing. Overall, recommendations arising from this study provide academic nurse administrators with strategies to effectively support them during a time when changes are needed within undergraduate curricula in Canadian Schools of Nursing. 


\section{Methods, Sample and Data Collection Procedures}

A detailed discussion of the study methodology has been reported in part A (AUTHOR, 2020). The research involved the dissemination of two surveys; one directed to nurse leaders in administrative roles while the other directed to nurse educators. Additional qualitative data was collected through a focus group and one-on-one telephone interviews; the majority of interview and focus group participants held nurse educator rather than administrator roles.

A convenience sample of Deans, Directors, and Chairs of all CASN accredited Schools of Nursing ( $n=94$ ) were invited to participate in the study. An anonymous survey comprised of 34 questions addressed their perceptions of the following: (1) educators' informatics/digital health knowledge; (2) educators' use of CASN informatics resources; (3) current informatics/digital health teaching and curricular integration; (4) digital health supports provided to nurse educators; and (5) value of informatics/digital health integration in nursing education.

A panel of 10 digital health experts (researchers and educators) vetted the survey for readability, clarity, comprehensiveness, and length to ascertain its face validity. Feedback received was reviewed and incorporated into the survey before hosting it electronically via the Lime Survey platform provided by Canada Health Infoway. CASN assumed the responsibility for disseminating the survey, primarily through email invitations that included an embedded link to the survey in French and English. Data collection occurred between May-October 2018, with periodic reminders provided by CASN to achieve a representative sample. Survey data were stored on a secure server with access limited to the Infoway support staff who provided periodic data downloads to the research team to monitor response rate. Ethics approval was obtained from the Ethics and Research Board at the Researchers' institution.

\section{Results}




\section{Participant Characteristics}

The respondents to the survey $(n=35)$ included 17 Deans, Directors and Chairs, 5 Associate Deans-Academic, and an additional 13 individuals with a variety of administrative titles (e.g., Program Manager, Coordinator, Assistant Dean). These individuals represented 18 different University level schools of nursing and 9 schools at the college level. Some schools had more than one administrative response to the survey.

The academic nurse administrator sample included cross-country representation with $43 \%$ from Ontario, $40 \%$ from the Western region, $8.6 \%$ from the Atlantic region and another $8.6 \%$ from other parts of the country (e.g., Nunavut). Years of experience varied, with a majority (34.3\%) reporting more than 6 years of experience. The administrative work of a majority was focused on undergraduate nursing programs $(n=33)$, with 11 reporting engagement with a graduate program and 3 others working within the context of an interprofessional program. Most administrators reported their digital health/informatics competency as being at the beginner $(41 \%)$ or intermediate level $(50 \%)$.

\section{Perceptions of Educator Informatics/Digital Health Competency}

Administrator perspectives on those educators with digital health competency or knowledge varied. Fifteen administrators rated educators with digital health competency as greater than $40 \%$ while most $(n=20)$ reported that less than $40 \%$ held relevant digital health competency (Figure 1). There was some inconsistency in how administrators defined digital health competence, 


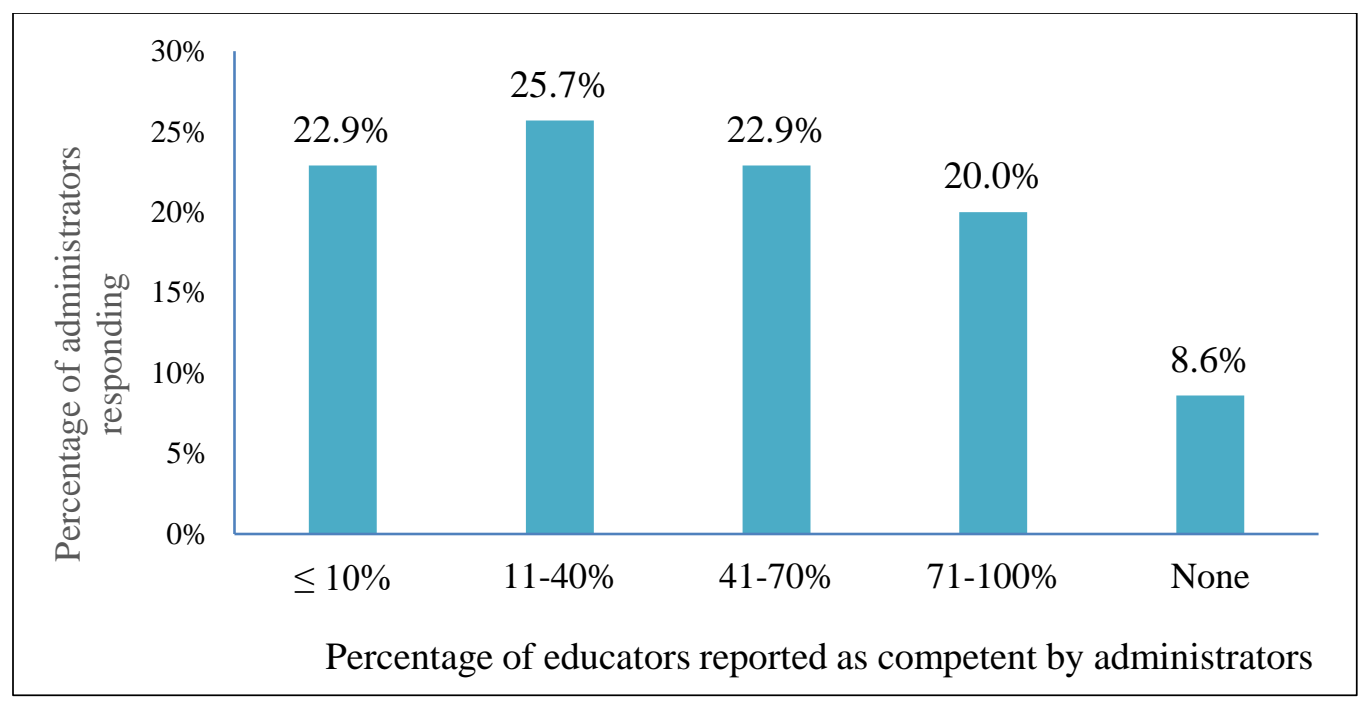

Figure 1. Perception of educators' digital health competency.

made evident in the qualitative data from open text survey responses and interviews. As one administrator within a Director role indicated:

"We need to grow this competency. Collaboration (interprofessional) is important regarding the technology required in the learning environment."

In comparison, another Dean described digital health integration in the following manner:

"There were two things we had to learn as a faculty and as a college of nursing. There is the mechanics of the equipment and then there is the delivery of the class and the pedagogy that is needed - we never allowed the equipment or the technology to drive the need".

\section{Current Curricular Integration of Informatics/Digital Health}

Within the survey, administrators were asked a number of questions about current curricular integration and teaching relevant to digital health and informatics. Questions also focused on their perceptions of educators' use of various resources developed by CASN to increase educators' digital health capacity.

Educator use of CASN resources. Administrators indicated their educators moderately to extensively (63\%) used CASN entry-to-practice informatics competencies to support student learning in their programs, however other resources were used less extensively (Table 1). 
Table 1. Administrator Views of Educator Use of CASN Resources ( $n=35)$.

\begin{tabular}{llllll}
\hline & Not at all & Minimally & Moderately & Extensively & Unknown \\
\hline Entry-to-practice informatics competencies & $6 \%$ & $11 \%$ & $49 \%$ & $14 \%$ & $20 \%$ \\
Faculty Teaching Toolkit & $14 \%$ & $23 \%$ & $37 \%$ & $0 \%$ & $26 \%$ \\
Consumer Health Solutions Resource & $26 \%$ & $34 \%$ & $6 \%$ & $0 \%$ & $34 \%$ \\
Social Media whiteboard animation & $29 \%$ & $23 \%$ & $3 \%$ & $3 \%$ & $43 \%$ \\
Clinical Data Standards whiteboard animation & $31 \%$ & $26 \%$ & $0 \%$ & $3 \%$ & $40 \%$ \\
\hline
\end{tabular}

Teaching related to select informatics competency indicators. As shown in Table 2,

administrators indicated educators address some informatics competency indicators in their teaching, reporting an emphasis on the use of credible web sites and Internet resources, multimedia applications, and legal and regulatory requirements associated with the use of ICTs.

Table 2. Administrator ( $n=35)$ Perceptions of Competency Indicators Being Addressed by Educators

\begin{tabular}{|c|c|c|c|c|c|}
\hline & $\begin{array}{c}\text { Not at } \\
\text { all }\end{array}$ & Minimally & Moderately & Extensively & Unknown \\
\hline $\begin{array}{l}\text { Use specific application of } \\
\text { ICTs such as electronic } \\
\text { health record (EHR) } \\
\text { application. }\end{array}$ & 5.7 & 17.1 & 31.4 & 34.3 & 11.4 \\
\hline $\begin{array}{l}\text { Mobile devices and apps } \\
\text { (e.g., smartphone apps). }\end{array}$ & & 42.9 & 31.4 & 22.9 & 2.9 \\
\hline $\begin{array}{l}\text { Credible and relevant World } \\
\text { Wide Web sites and Internet } \\
\text { resources. }\end{array}$ & & & 31.4 & 65.7 & 2.9 \\
\hline $\begin{array}{l}\text { Social networking } \\
\text { applications (e.g. Twitter, } \\
\text { Facebook). }\end{array}$ & 8.6 & 57.1 & 20 & 2.9 & 11.4 \\
\hline $\begin{array}{l}\text { Multimedia applications (e.g. } \\
\text { podcasts, blogs, YouTube). }\end{array}$ & & 11.4 & 51.4 & 34.3 & 2.9 \\
\hline $\begin{array}{l}\text { Standardized nursing and } \\
\text { other clinical terminologies } \\
\text { (e.g., International }\end{array}$ & 5.7 & 28.6 & 31.4 & 11.4 & 22.9 \\
\hline
\end{tabular}


Classification of Nursing Practice).

Legal and regulatory

\section{7}

45.7

8.6

requirements, ethical

standards, and organizational

policies and procedures (e.g.

privacy and security).

Education and teaching related to electronic health records. A majority of

administrators (62\%) reported students receive electronic health record training before clinical

placements whereas $68 \%$ reported students receive this preparation during their clinical

placements. Only $32.4 \%$ reported that their program utilizes a simulated electronic health record

system in conjunction with their simulation-skills laboratory teaching activities although $30.4 \%$

reported there are concrete plans to do this in the near future. The current variability in digital

health use within practice environments was identified as a significant issue for several

respondents. For example, one respondent explained:

"We are currently waiting for the hospital in our [----] to adopt a new electronic documentation and then we will purchase one for our lab to provide training for the students. "(Chair)

Another respondent indicated:

"our health authority is implementing the EHR, we are working with them to provide training for our students, but currently this does not take place".

(Associate Dean, Academic)

Whereas another respondent commented:

"Currently none of our practice placements [settings] use digital/electronic charting."

(Chair)

It is apparent but not surprising that the evolution of digital health remains widely varied across settings and jurisdictions, making it challenging for Schools of Nursing to consistently prepare students for practice supported by ICTs. 
Integration of digital health/informatics in the curriculum. Eighty two percent of administrators indicated integration of digital health/informatics content into undergraduate curricula, including: classroom (66\%), clinical settings (60\%), and simulation laboratory (51\%). Further a majority of administrators indicated educators in their School of Nursing have requisite competencies and knowledge to teach digital health (71\%), but 26.5\% did not know. Educators were also reported to be delivering digital health content within interprofessional programs $(26.5 \%)$.

Support for nurse educators. Only $29 \%$ of administrators reported having a team or committee in place to facilitate the integration of digital health/informatics into their nursing program(s). A majority of administrators (62.5\%) indicated they believed it would be helpful to establish such a committee. Forty-seven percent indicated there are onsite opportunities for educators to receive digital health/informatics training and education. Participation in the CASN Digital Health Faculty Peer Network (DHFPN) by faculty members was indicated by only $23.5 \%$ of the respondents. Of these, a majority (62.5\%) participated as mentors or peer leaders, but none as mentees while $37.5 \%$ reported members of their faculty either participated in a workshop or webinar offered by the DHFPN.

Value of digital health/informatics in nursing education. Administrators agreed or strongly agreed $(71 \%)$ the CASN informatics entry-to-practice competencies are essential to undergraduate success. Further, $82 \%$ indicated their belief (agreed/strongly agreed) that digital health/informatics has the potential to significantly contribute to improving the quality of care delivery. The importance of administrative support for increasing the digital health capacity among nurse educators and graduates was agreed or strongly agreed to by $79 \%$ of the 
administrators. In addition, there is a sense that more administrative support is necessary; as one participant noted:

"I have been a champion of the CASN digital health competencies and tools for a long time but the uptake has been far too low, with enormous amount of resistance and conflict. Culture shifts are hard, and this one is taking a lot of work and we do not have consistent, ongoing support. I have proposed a new role for our department, with HR support; however, it has not been approved by our Dean, to date. My honest feelings are that I need assistance achieving further success." (Chair)

Some administrators acknowledged there are opportunities for effecting change and bringing more emphasis on digital health/informatics education within their program. As noted by one respondent:

"currently a major curriculum revision is underway and the integration of digital health is a priority." (Dean)

Other comments suggested they have a limited awareness of the actual level of digital health integration given their role or position. For example:

"the Department Head for BScN program would have more intimate knowledge about the skills and abilities of faculty than I do." (Dean)

whereas another administrator indicated:

"Digital competencies are not required by [----]. I have no idea if my faculty [are] competent in digital matters. So I am not sure the accuracy of my responses." (Position unknown)

Similarly, when asked about faculty awareness of CASN entry-level NI competencies one administrator openly acknowledged:

To be brutally honest with you I don't even think they knew they existed, and we [have]never used them.

Overall, a majority of administrators acknowledged the value of digital health/informatics content in the undergraduate curriculum but their awareness of current integration and faculty competency to successfully achieve the same was varied. 


\section{Discussion}

In this study, Canadian academic nurse administrators and educators were invited to provide their perspectives on the current state of digital health/informatics content integration into nursing curricula. The following discussion focuses on the findings from the administrator survey and provides comparative results relative to some of the findings from the nurse educator survey previously reported (AUTHOR, 2020).

Comparing administrator and educator perspectives. Overall, administrator respondents perceived educators to be reasonably well prepared to teach the core nursing informatics competencies required of nurses in Canada and deliver digital health content in undergraduate curricula to fulfill these requirements. When comparing educators and administrators, both agreed on the importance of digital health and informatics; however, their views were somewhat divergent regarding the supports available to educators for the integration of the same (Figure 2).

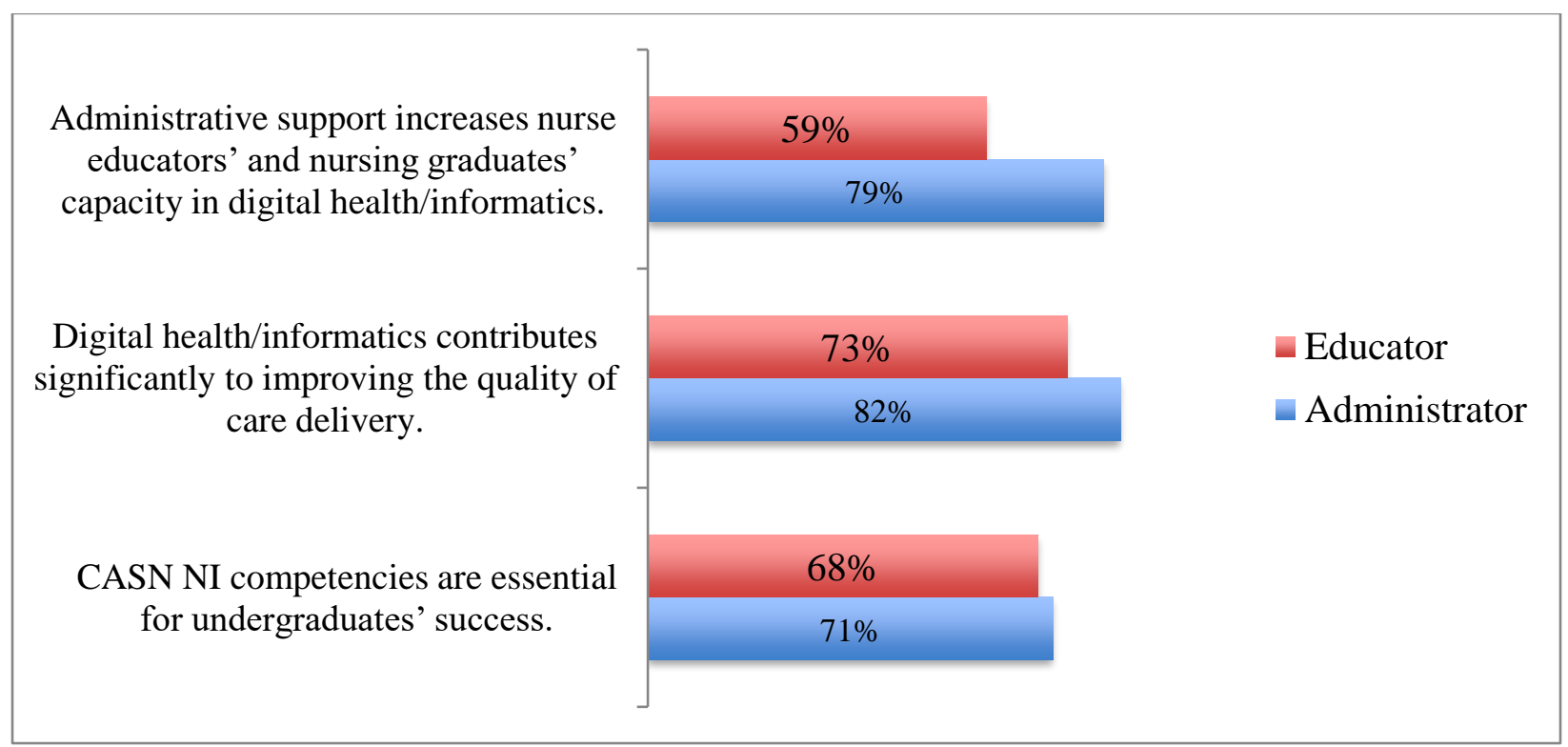

Figure 2. Educator $(n=360)$ and administrator $(n=35)$ views on administrative support, digital health, and NI competencies. 
Administrators' views of faculty capacity to deliver digital health/informatics provided a starkly contrasting view to that of nurse educators (AUTHOR, 2020); there is a clear misalignment of confidence and perceived ability of educators to teach informatics (see Table 3).

Table 3. Comparison of Administrator $(n=35)$ and Educator $(n=360)$ Perceptions of

\section{Confidence}

\begin{tabular}{llccc}
\hline & & Yes & No & NA/Unsure \\
\hline $\begin{array}{l}\text { Educators' } \\
\begin{array}{l}\text { Perceptions of } \\
\text { Confidence }\end{array}\end{array}$ & $\begin{array}{l}\text { I am confident that I have the requisite } \\
\text { competencies, knowledge and skills to } \\
\text { teach basic digital health/informatics } \\
\text { content. }\end{array}$ & $34 \%$ & $59 \%$ & $7 \%$ \\
\cline { 2 - 5 } & $\begin{array}{l}\text { I feel confident in my ability to integrate } \\
\text { digital basic health/informatics content in } \\
\text { my teaching assignments. }\end{array}$ & $48 \%$ & $43 \%$ & $9 \%$ \\
\hline $\begin{array}{l}\text { Administrators' } \\
\begin{array}{l}\text { Perceptions of } \\
\text { Educators' } \\
\text { confidence }\end{array}\end{array}$ & $\begin{array}{l}\text { Within our undergraduate-nursing } \\
\text { program there are educators with requisite } \\
\text { knowledge and skills required to teach } \\
\text { digital health/informatics. }\end{array}$ & $\mathbf{7 0 . 6}$ & $\mathbf{2 . 9}$ & $\mathbf{2 6 . 5}$ \\
\hline
\end{tabular}

A comparison of survey responses also demonstrated that administrator perspectives differ from those of educators in relation to CASN resource use (see Table 4). It appears that administrators believe their faculty are making more progress on digital health/informatics integration than educators report.

Table 4. A Comparison of Administrator $(n=35)$ and Educator (shaded) ( $n=360)$ Reporting of CASN Resource Use

\begin{tabular}{llllll}
\hline Informatics Teaching Resources & Not at all & Minimally & Moderately & Extensively & Unknown \\
\hline \multirow{2}{*}{ Entry-to-Practice Informatics Competencies } & $\mathbf{6 \%}$ & $\mathbf{1 1 \%}$ & $\mathbf{4 9 \%}$ & $\mathbf{1 4 \%}$ & $\mathbf{2 0 \%}$ \\
\cline { 2 - 6 } & $28 \%$ & $33 \%$ & $19 \%$ & $12 \%$ & $8 \%$ \\
\hline \multirow{2}{*}{ Faculty Teaching Toolkit } & $\mathbf{1 4 \%}$ & $\mathbf{2 3 \%}$ & $\mathbf{3 7 \%}$ & $\mathbf{0 \%}$ & $\mathbf{2 6 \%}$ \\
\hline Consumer Health Solutions Resource & $48 \%$ & $26 \%$ & $18 \%$ & $3 \%$ & $5 \%$ \\
\hline
\end{tabular}




\begin{tabular}{llllll}
\cline { 2 - 6 } & $67 \%$ & $17 \%$ & $6 \%$ & $1 \%$ & $9 \%$ \\
\hline \multirow{3}{*}{ Social Media Whiteboard Animation } & $\mathbf{2 9 \%}$ & $\mathbf{2 3 \%}$ & $\mathbf{3 \%}$ & $\mathbf{3 \%}$ & $\mathbf{4 3 \%}$ \\
\cline { 2 - 6 } & $74 \%$ & $14 \%$ & $5 \%$ & $1 \%$ & $6 \%$ \\
\hline \multirow{2}{*}{ Clinical Data Standards Whiteboard Animation } & $\mathbf{3 1 \%}$ & $\mathbf{2 6 \%}$ & $\mathbf{0 \%}$ & $\mathbf{3 \%}$ & $\mathbf{4 0 \%}$ \\
\cline { 2 - 6 } & $79 \%$ & $10 \%$ & $3 \%$ & $2 \%$ & $6 \%$ \\
\hline
\end{tabular}

These findings suggest more research is warranted to further understand why such discrepancy exists, and to identify current challenges within individual Schools of Nursing. Given the nurse educators' group was comparatively much larger $(n=360)$ than the administrator group $(n=35)$, these findings call for further investigation.

Findings related to educators' perspectives on their knowledge and capacity to teach informatics, although contradictory to those of administrators in this study, are congruent with previous research. The literature on nurse educators' experiences with digital health/informatics integration suggests that a multitude of issues influence nurse educators' ability to fulfill demands related to digital health education and curricular integration. In 2008, Fetter noted the following struggles and key issues to be addressed to improve graduate outcomes in this area: 1) inconsistent integration of informatics in clinical and theory courses, 2) variability in clinical information systems in clinical sites, 3) lack of educational policies regarding students' and faculty members' access and use of technology in clinical sites, 4) concerns regarding medication errors, confidentiality, privacy and security, and 5) faculty knowledge, skills, and motivation to integrate informatics. Regrettably, each of these issues persist in Canada and warrant further discussion within the context of nursing education. While the technological context of clinical practice environments is beyond the control of academic nurse administrators, all of the others are within their purview and need to be systematically addressed. 
Research involving program curricula leaders and administrators has identified similar challenges associated with digital health/informatics integration in nursing education. For example, Larson (2017) conducted semi-structured interviews with 9 baccalaureate nursing program leaders in the United States to explore their perceptions and experiences related to NI. Findings affirmed the importance of NI but revealed challenges related to agreeing on a definition of NI, availability of resources, faculty development, and legal and ethical issues (Larson, 2017).

Addressing these challenges requires extensive involvement and leadership on the part of academic program administrators to ensure alignment between curriculum plans and practice setting requirements. For example: there is a need to create more opportunities for students to learn about healthcare technologies during their undergraduate education (Brooks \& Erickson, 2012), provide more preparation and support to advance the use of informatics tools to support educational processes such as distance learning and simulation (Nguyen, Zierler, \& Nguyen, 2011), and distinguish applications of technology used for learning and teaching versus those used in the context of clinical practice settings (Fetter, 2009a; AUTHOR, 2013). Ideally, academic administrators should aim to establish strategic and collaborative partnerships with clinical agencies to align goals of both entities toward improved outcomes of care and education (Fetter, 2009b).

Finally, findings suggest there are still many who view computer literacy as equivalent to informatics competency. An understanding of the entry-to-practice informatics competencies would go a long way to remedy this confusion as computer literacy is a prerequisite to the mastery of same. Comments focused on the use of teaching and learning technologies (e.g., learning management systems and presentation software) rather than digital health technologies 
reflect a further lack of clear understanding of the needed curricular content. Fundamental clarification of digital health, what it is and is not, and why it matters in undergraduate nursing curricula is now an imperative focus for all School of Nursing administrators.

As Rajalahti, Heinonen, and Saranto (2014) noted, "NI [Nursing Informatics]-related concepts, definition, and competencies are not necessarily obvious for educator programmes, nurse educators in faculties or leaders in healthcare practice" (p. 49). Among others, agreement on which aspects of NI are to be integrated in curricula, is a persistent challenge (Larson, 2017). Informatics remains an unfamiliar domain of practice for many academic nurse administrators and educators alike. While NI was initially identified as a specialty practice with the recognition of the specialized nurse informatician role (Bickford, 2007; 2015), in recent times NI has proved relevant and essential to nurses in every practice role (CNA \& CNIA, 2017; Remus \& Kennedy, 2012).

The Institute of Medicine considers informatics a core competency of health professionals' practice, essential to fulfilling other core competencies including working in interdisciplinary teams, providing patient-centered care, employing evidence-based practice and applying quality improvement (Greiner \& Knebel, 2003). As such, nurse scholars worldwide have advocated and worked extensively to define core NI competencies for entry to practice and to accelerate the integration of informatics into nursing education (AUTHOR, 2017). More recently, informatics competencies have further evolved to include specific articulation as per various nursing roles, such as nurse practitioners (Curran, 2003), tele-health (van Houwelingen, Moeman, Ettema, Kort, \& ten Cate, 2016), and nurse managers (Hart, 2010).

Focused efforts to define nurse leaders' informatics competencies have been recently reported in the United States (Collins, Yen, Phillips, \& Kennedy, 2017) and Canada (AUTHOR, 
2019). Given their unique strategic involvement in decision making related to acquisition and deployment of digital health technologies, these efforts have been largely directed to the knowledge and skills required by nurse leaders in clinical practice settings. However, these competencies are also very relevant to nurse leaders in academic settings. Canadian nurse leaders in post-secondary institutions are encouraged to reflect upon these competencies and use them to guide strategic planning related to informatics education within their programs.

Interestingly, despite the great emphasis on increasing informatics capacity in nursing education and the extensive informatics competency development work to date, there is limited attention to nurse educators' competency in informatics with the last published work on this topic dating back to the eighties (Peterson \& Gerdin-Jelger, 1988). The identification of these competencies would provide academic nurse administrators and educators a clearer understanding of how digital health/informatics applies to their roles and may help to accelerate and reinforce their engagement in the digital health/informatics agenda.

Another potential contributing factor to the limited understanding of informatics among administrators and educators might be related to the existence of many different yet related terms (e.g., health informatics, eHealth, digital health, clinical informatics, nursing informatics, consumer health informatics). Providing clarity and delineation of the meaning of each is an important first step in securing a foundational understanding for administrators and educators alike.

Recommendations for academic nurse administrators. The academic nurse administrator is charged with ensuring the delivery of relevant curricula to appropriately prepare future graduates for contemporary nursing practice (Bouws, 2018). In the absence of adequate preparation for the use of ICTs in clinical practice, graduated nurses may receive only functional 
preparation for their use in the workplace. If not addressed in the academic realm, the opportunity to prepare nurses to integrate and critically apply these tools in practice is likely to be lost. Rather than perceiving these tools as ways to collect data, nurses should view ICTs as essential resources to inform their critical thinking in real time, setting the stage for advanced predictive and retrospective data analytic capabilities. The foundation for such skills is ideally entrenched during undergraduate education, when the importance of evidence or research informed practice is established. In time, evidence will be dynamically generated from practice, with assessments, interventions and associated outcomes captured real time in electronic health records and presented to clinicians for more timely decision-making at the point of care.

Although beyond the scope of this research, the digital health/informatics competency of administrators in Schools of Nursing is critical in supporting necessary knowledge development among educators and the achievement of successful curricular integration. Since digital health/informatics competencies have yet to be delineated for academic administrators and educators, as a beginning step each group is encouraged to evaluate and address their respective learning needs in relation to the CASN entry-to-practice informatics competencies (CASN, 2012). Administrators will also find there are relevant role competencies among those identified for nurse administrators in clinical practice settings (AUTHOR, 2019). Providing strategic leadership for relevant curricular transformation necessitates that administrators acquire the requisite knowledge and understanding in order to guide educators and inform the appropriate preparation of students.

Despite the differences noted in our study, it is clear both administrators and educators agree on the value of digital health and informatics. These positive views are promising; nurse administrators can capitalize on educators' strengths and desires to further develop their 
competency and confidence to integrate digital health into curricula. Although there may be champions to lead the work of integration, all educators should be charged with the responsibility for teaching digital health/informatics related content. In order for educators to do so, there needs to be multi-faceted strategies to ensure educators are supported in acquiring this knowledge, and the provision of resources to ensure they are able to effectively integrate digital health/informatics into their teaching practices and curricula (Gassert, 2008; Curran, 2008; Fetter, 2008; Fetter, 2009a; Fetter, 2009b; Rajalahti et al, 2014; Larson, 2017; Risling, 2017; Connors, Skiba, Jeffries, Rizzolo, \& Billings, 2017; Foster \& Sethares, 2017; Skiba, 2017). A suggested beginning step is to conduct a learning needs assessment of educators in the area of digital health/informatics with the results used to inform the planning and development of relevant and targeted professional development programs. Additionally, support could be channelled for continuing education (e.g., conferences and workshops) and other informatics knowledge development activities (e.g., courses, certification). Educators should also be encouraged to participate in nursing informatics networking activities, including engagement in local and national specialty groups and to make use of widely accessible NI self-study educational resources, such as the CASN resources mentioned earlier.

Other recommendations for academic administrators to consider include:

1) Identifying educators with an interest in digital health/informatics and designate them as program leads;

2) Supporting those charged with the curricular integration of digital health content by affording them the time to complete this work;

3) Establishing a collaborative working group (including administrators, educators and clinical partner agencies) to focus on the development of a digital health/informatics 
curricular integration. The inclusion of stakeholder views and expectations for student and graduate ICT use will provide further alignment between academia and clinical practice.

4) Adopting a simulated EHR as a pedagogical tool to support teaching of clinical skills in laboratory settings. This strategy has the potential to encourage students to begin to use EHR data and information in the planning, documentation, and evaluation of clinical care prior to actual clinical practice.

5) Using curricular revisions and/or accreditation planning to guide digital health content integration within the nursing curricula.

6) Adapting existing competencies by CASN or others to identify a set of core digital health/informatics competencies for academic nurse administrators and educators. Academic administrators are accountable and are genuinely interested in ensuring nursing graduates are well prepared to lead transformative changes within their communities and beyond (Huston, 2008; Risling, 2017). As such, they need to purposely engage faculty members in focused work to address digital health/informatics requirements within undergraduate curricula. In addition, a collaborative dialogue between nurse informatics leaders and the CASN accrediting body is a necessary and rather time sensitive next step: Educational standards must include clearly articulated digital health requirements - the authors proffer that revised standards will strengthen the emphasis placed upon digital health/informatics content integration within undergraduate programs across Canada.

\section{Limitations}

Given the low response rate and small sample size, these findings are not generalizable to all Schools of Nursing in Canada. These findings represent views of survey respondents and may 
not represent all instances of digital health integration into undergraduate nursing programs in Canada. Although the administrator participants in this study were likely educators themselves, there were some differences in their perspectives from those of the educators, suggesting the need for further research. Their views may well have been influenced by the experience and expectations of the administrator role. There may also have been response bias as individuals interested in the topic of digital health might have been more inclined to participate in the study.

\section{Conclusion}

"An understanding of the business of healthcare and its influence on the practice of nursing is required to create an environment in which the mission of nursing can be expressed and education of future practitioners becomes possible (Ferguson-Paré, 2003, p. 35)."

The science and practice of informatics have evolved in recent years with applicability across various sectors and disciplines, including nursing and healthcare. This study has shed some light on the status of digital health/informatics integration within Canadian Schools of Nursing. The focus of this paper was on academic nurse administrators' perspectives; findings related to educators' perspectives (Part A) have also been published (AUTHOR, 2020). Overall, administrators of nursing programs are engaged and enthused to embrace digital health/informatics and there is some evidence to suggest that integration is already occurring within their programs. Administrators are uniquely positioned to support and facilitate access to resources that will further advance educator capacity to integrate digital health/informatics into nursing education. Nonetheless, more research is needed to understand some of the unique aspects challenging both administrators and educators to achieve this goal.

The COVID-19 pandemic has illustrated the potential of digital health solutions to supplant traditional in-person care with virtual care, as well as support effective outbreak 
management (Denadai, 2020; Peek, Sujan \& Scott, 2020; Whitelaw et al, 2020). The current pandemic has also provided an unprecedented catalyst in accelerating the uptake of these technologies across the globe. While the permanence of some solutions remains to be seen, there are clear indications we have glimpsed a potential future for the delivery of healthcare services. Hence the integration of digital health into every School of Nursing curriculum across Canada is no longer an option but an imperative and time sensitive requirement. Digital health tools and approaches are central to contemporary nursing practice; for the sake of your students and Canadian healthcare, the time to act is now!

\section{References}

American Medical Informatics Association [AMIA] (n.d a). What is informatics? [Fact Sheet]. Retrieved from: https://www.amia.org/fact-sheets/what-informatics

American Medical Informatics Association [AMIA] (n.d b). Clinical informatics. Retrieved from: https://www.amia.org/applications-informatics/clinical-informatics

Bickford, C. J. (2007). The specialty practice of nursing informatics. CIN: Computers, Informatics, Nursing, 25(6), 364-366.

Bickford, C. J. (2015). The specialty of nursing informatics: New scope and standards guide practice. CIN: Computers, Informatics, Nursing, 33(4), 129-131 3p. doi:10.1097/CIN.0000000000000150

Bouws, M. (2017). The nursing dean role: An integrative review. Nursing Education Perspectives 39(20), 80-84.

Brooks, C.L. \& Erickson, L.K. (2012). What is the solution for clinical nurse educators and the electronic medical record? Teaching and Learning in Nursing, 7: 129-132. doi.org/10.1016/j.teln.2012.06.003

Canadian Association of Schools of Nursing. (2019). Digital health. Retrieved from https://digitalhealth.casn.ca/

Canadian Association of Schools of Nursing. (2012). Nursing informatics entry-to-practice competencies for registered nurses. Ottawa, ON: Author. Retrieved from https://www.casn.ca/2014/12/casn-entry-practice-nursing-informatics-competencies/ 
Canadian Association of Schools of Nursing. (2013). Nursing informatics teaching toolkit: Supporting the integration of the CASN nursing informatics competencies into nursing curricula. Ottawa, ON: Author. Retrieved from http://www.casn.ca/2014/12/nursinginformatics-teaching-toolkit/

Canadian Association of Schools of Nursing. (2016). Consumer health solutions: A teaching and learning resource for nursing education. Ottawa, ON: Author. Retrieved from http://www.casn.ca/wp-content/uploads/2016/04/Consumer-Health-Solutions-Ateaching-and-learning-resource-for-nursing-education-EN.pdf

Canadian Association of Schools of Nursing. (2015). National nursing education framework: Final report. Ottawa, ON: Author. Retrieved from https://www.casn.ca/wpcontent/uploads/2014/12/Framwork-FINAL-SB-Nov-30-20151.pdf

Canadian Association of School of Nursing. (n.d). About-CASN. Retrieved from: https://www.casn.ca/about-casn/casnacesi-mission/

Canada Health Infoway (n.d). What is digital health? Retrieved from: https://www.infowayinforoute.ca/en/what-we-do/benefits-of-digital-health/what-is-digital-health

Canada Health Infoway. (2017). National survey of Canadian nurses: Use of digital health technology in practice. Ottawa, ON: Author. Retrieved from https://www.infowayinforoute.ca/en/component/edocman/3320-2017-national-survey-of-canadian-nurses-useof-digital-health-technology-in-practice/view-document

Canadian Nurses Association and Canadian Nursing Informatics Association. (2017). Nursing informatics [joint position statement]. Ottawa, ON: Authors. Retrieved from https://www.cna-aiic.ca/ /media/cna/page-content/pdf-en/nursing-informatics-jointposition-statement.pdf?la=en

Collins, S., Po-Yin Yen, Phillips, A., \& Kennedy, M. K. (2017). Nursing informatics competency assessment for the nurse leader. Journal of Nursing Administration, 47(4), 212-218. doi:10.1097/NNA.0000000000000467

Connors, H. B., Skiba, D. J., Jeffries, P. R., Rizzolo, M. A., \& Billings, D. M. (2017). Health information technology scholars program: From implementation to outcomes. Nursing Education Perspectives, 38(1), 3-8. doi:10.1097/01.NEP.0000000000000102

Curran, C. R. (2003). Informatics competencies for nurse practitioners. AACN Clin Issues; 14(3):320-330 
Curran, C. R. (2008). Faculty development initiatives for the integration of informatics competencies and point-of-care technologies in undergraduate nursing education. The Nursing Clinics of North America, 43(4), 523. doi:10.1016/j.cnur.2008.06.001

Darvish, A., Bahramnezhad, F., Keyhanian, S., \& Navidhamidi, M. (2014). The role of nursing informatics on promoting quality of health care and the need for appropriate education. Global Journal of Health Science, 6(6), 11-18. doi:10.5539/gjhs.v6n6p11

Denadai, Rafael. (2020). COVID-19 Pandemic as a Driver for Spreading Virtual Care Globally: The Future Starts Now. Clinics, 75, e1967. Epub May 29, 2020. https://doi.org/10.6061/clinics/2020/e1967

Driessnack, M., Sousa, V. D., \& Mendes, I. A. C. (2007). An overview of research designs relevant to nursing: Part 2: Mixed and multiple methods. Rev.Latino-Am.Enfermagem, 15 (5). Retrieved from: http://www.scielo.br/scielo.php?script=sci_arttext\&pid=S010411692007000500025

Engelbright, J. \& Perlin, J. (2008). The chief nurse executive role in large healthcare systems. Nursing Administration Quarterly 32(3), 188-194.

Ferguson-Paré, M. (2003). Administration: What is leadership in nursing administration? Nursing Leadership, 16(1), 35-37. Retrieved from https://www.longwoods.com/product/16240

Fetter, M. S. (2008). Enhancing baccalaureate nursing information technology outcomes: Faculty perspectives. International Journal of Nursing Education Scholarship, 5, Article3. doi:10.2202/1548-923X.1440

Fetter, M. S. (2009a). Curriculum strategies to improve baccalaureate nursing information technology outcomes. The Journal of Nursing Education, 48(2), 78-85.

Fetter, M. S. (2009b). Collaborating to optimize nursing students' agency information technology use. CIN: Computers, Informatics, Nursing, 27(6), 354-362. doi:10.1097/NCN.0b013e3181bca7be

Foster, M., \& Sethares, K. (2017). Current strategies to implement informatics into the nursing curriculum: An integrative review. Online Journal of Nursing Informatics, 21(3) Retrieved from https://www.himss.org/library/current-strategies-implement-informaticsnursing-curriculum-integrative-review 
Gassert, C. A. (2008). Technology and informatics competencies. The Nursing Clinics of North America, 43(4), 507. doi:10.1016/j.cnur.2008.06.005

Greiner, A. C., \& Knebel, E. (2003). The core competencies needed for health care professionals. In A. C. Greiner, \& E. Knebel (Eds.), Health professions education: A bridge to quality (Chapter 3). Washington, DC: National Academies Press (US). Retrieved from https://www.ncbi.nlm.nih.gov/books/NBK221519/

Hart, M. D. (2010). A Delphi study to determine baseline informatics competencies for nurse managers. CIN: Computers, Informatics, Nursing, 28(6), 364-370. doi:10.1097/NCN.0b013e3181f69d89

Huston, C. (2008). Preparing nurse leaders for 2020. Journal of Nursing Management, 16, 905911.

Huston, C. (2013). The impact of emerging technology on nursing care: Warp speed ahead. Online Journal of Issues in Nursing, 18(2), 1-1.

International Medical Informatics Association [IMIA]. (2009). The nursing informatics special interest group-definition of nursing informatics. Retrieved from https://imianews.wordpress.com/2009/08/24/imia-ni-definition-of-nursing-informaticsupdated/

Larson, L. R. (2017). Perceptions and experiences of baccalaureate nursing program leaders related to nursing informatics. (Doctoral Dissertation). Retrieved from ProQuest LLC.

Morton, P.G. (2014). Preparing the next generation of academic Chief Nurse Administrators. Journal of Professional Nursing 30(4), 279-280.

Nelson, R. \& Staggers, N. (2018). An introduction to health informatics. In R. Nelson, \& N. Staggers (Eds.), Health informatics: An interprofessional approach (2nd ed., pp. 1-9). St. Louis, MO: Elsevier-Mosby.

Nguyen, D. N., Zierler, B., \& Nguyen, H. Q. (2011). A survey of nursing faculty needs for training in use of new technologies for education and practice. The Journal of Nursing Education, 50(4), 181-189. doi:10.3928/01484834-20101130-06

Peek, N., Sujan, M., Scott, P. (2020). Digital health and care in pandemic times: impact of COVID-19. BMJ Health Care Informatics 27(e100166). doi:10.1136/ bmjhci-2020100166 
Pepito, J.A. \& Locsin, R. (2019). Can nurses remain relevant in a technologically advanced future? International Journal of Nursing Sciences, 6, 106-110.

Peterson, H.E. \& Gerdin-Jelger, U. (1988). Preparing nurses for using information systems: recommended informatics competencies. New York: National League for Nursing.

Rajalahti, E., Heinonen, J., \& Saranto, K. (2014). Developing nurse educators' computer skills towards proficiency in nursing informatics. Informatics for Health \& Social Care, 39(1), 47-66. doi:10.3109/17538157.2013.834344

Remus, S., \& Kennedy, M. A. (2012). Innovation in transformative nursing leadership: Nursing informatics competencies and roles. Nursing Leadership (Toronto, Ont.), 25(4), 14-26.

Risling, T. (2017). Educating the nurses of 2025: Technology trends of the next decade. Nurse Education in Practice, 22, 89-92. doi:10.1016/j.nepr.2016.12.007

Skiba, D. J., Connors, H. R., \& Jeffries, P. R. (2008). Information technologies and the transformation of nursing education. Nursing Outlook, 56(5), 225-230. doi:10.1016/j.outlook.2008.06.012

Skiba, D. J. (2017). Horizon report: Knowledge obsolescence, artificial intelligence, and rethinking the educator role. Nursing Education Perspectives (Wolters Kluwer Health), 38(3), 165-167. doi:10.1097/01.NEP.0000000000000154

U.S. National Library of Medicine (n.d). Definition of health informatics. Retrieved from: https://hsric.nlm.nih.gov/hsric_public/topic/informatics/

van Houwelingen, C.T.M., Moeman, A.H., Ettema, R.G.A., Kort, H.S.M., ten Cate, O. (2016). Competencies required for nursing telehealth activities: A Delphi-study. Nurse Educ Today;39:50-62. doi:10.1016/j.nedt.2015. 12.025

Whitelaw, S., Mamas, M.A., Topol, E., Van Spall, H.G.C. (2020). Applications of digital technology in COVID-19 pandemic planning and response. https://doi.org/10.1016/S2589-7500(20)30142-4.

World Health Organization (2019, March 26). Draft global strategy on digital health 2020-2024. Author: Geneva, Switzerland. Retrieved from: https://extranet.who.int/dataform/upload/surveys/183439/files/Draft\%20Global\%20Strate gy\%20on\%20Digital\%20Health.pdf 